$\xi_{p}$

\title{
Comparative Design and Analysis of Helical and Wave Spring
}

\author{
M. Muralidharan 1*, R.Aravinth 2, J.Gafferkhan3, R.Gandhi4 \\ ${ }^{1}$ VelTech HighTech Dr.Rangarajan Dr.Sakunthala Engineering College, \\ Avadi - 600 062, Tamilnadu, India. \\ ${ }^{2,3,4}$ VelTech HighTech Dr.Rangarajan Dr.Sakunthala Engineering College, \\ Avadi - 600 062, Tamilnadu, India. \\ *Corresponding authorE-mail: ${ }^{1}$ muralidharan@velhightech.com,mmurali09@yahoo.com
}

\begin{abstract}
:
This paper is a comparative between two springs such as helical and wave spring. Wave springs are precise flat wire compression springs that fit into assemblies that other springs cannot. These are used as an alternative spring for helical spring. Wave springs provide $50 \%$ reduction in spring height and axial space. They possess the same force and deflection as coil springs. They have reduced material requirements. They provide improved cost reduction. The Wave Spring has been subjected to Compression Test, Modal Analysis and Equivalent Elastic Strain Test and then compared to Helical Spring which again was subjected to the above same tests under the same conditions and parameters. The design of helical spring and wave spring has been done in CREO Parametric 4.0 and analysed in ANSYS R 18.1. The results are then compared.
\end{abstract}

Keywords: Spring comparison; Designing; Analyzing stress; strain concepts.

\section{Introduction}

Spring is an elastic object that stores mechanical energy. Springs are typically made of spring steel. There are many spring designs. In everyday use, the term often refers to coil springs. When a conventional spring, without stiffness variability features, is compressed or stretched from its resting position, it exerts an opposing force approximately proportional to its change in length (this approximation breaks down for larger deflections). The rate or spring constant of a spring is the change in the force it exerts, divided by the change in deflection of the spring. That is, it is the gradient of the force versus deflection curve. Springs are mainly used in the industry as members absorbing shock energy as well as for restoring the initial position of a part upon displacement for initiating a given function. A spring is defined as an elastic body, whose function is to compress when loaded and to recover its original shape when the load is removed. In other words, it is also termed as a resilient member. Springs are elastic bodies (generally made up of metals) that can be twisted, pulled, or stretched by some force. A spring is a flexible element used to exert a force or a torque and, at the same time, to store energy. Among the many types of springs, wave springs have attracted considerable attention this kind of long and reliable source of long lasting durability and considerable effectiveness than rest of the springs. An extension or compression spring's rate is expressed in units of force divided by distance, for example $\mathrm{lbf} / \mathrm{in}$ or $\mathrm{N} / \mathrm{m}$. A torsion spring is a spring that works by twisting. When it is twisted about its axis by an angle, it produces a torque proportional to the angle. A torsion spring's rate is in units of torque divided by angle, such as $\mathrm{Nm} / \mathrm{rad}$ or $\mathrm{ft} \cdot \mathrm{lbf} /$ degree. The inverse of spring rate is compliance, that is: If a spring has a rate of $10 \mathrm{~N} / \mathrm{mm}$, it has a compliance of $0.1 \mathrm{~mm} / \mathrm{N}$. The stiffness (or rate) of springs in parallel is additive, as is the compliance of springs in series.

Springs are made from a variety of elastic materials, the most common being spring steel. Small springs can be wound from prehardened stock, while larger ones are made from annealed steel and hardened after fabrication. Some non-ferrous metals are also used including phosphor bronze and titanium for parts requiring corrosion resistance and beryllium copper for springs carrying electrical current (because of its low electrical resistance).

\section{Material Used for springs}

Material chosen for the comparison of Helical Spring and Wave spring is Structural Steel.

Table.3: Material Properties

\begin{tabular}{|c|c|}
\hline Parameters & Value \\
\hline Tensile Yield strength & $2.5 \mathrm{e}+08 \mathrm{pa}$ \\
\hline Compressive yield strength & $2.5 \mathrm{e}+08 \mathrm{pa}$ \\
\hline Tensile ultimate strength & $4.6 \mathrm{e}+08 \mathrm{pa}$ \\
\hline Poison ratio & 0.3 \\
\hline Density & $7850 \mathrm{~kg} / \mathrm{m}-3$ \\
\hline Young's modulus & $2 \mathrm{e}+11 \mathrm{pa}$ \\
\hline
\end{tabular}


Structural steel is a category of steel used for making construction materials in a variety of shapes. Many structural steel shapes take the form of an elongated beam having a profile of a specific cross section. Sizes, chemical composition, mechanical properties such as strengths, storage practices, etc., of Structural Steel are regulated by standards in most industrialized countries.Most structural steel shapes, such as I-beams, have high second moments of area, which means they are very stiff in respect to their cross-sectional area and thus can support a high load without excessive sagging. Structures in which the individuals are made of steel and are joined by welding, riveting, or blasting. Due to the high quality of steel, these structures are dependable and require less material than different sorts of structures. Steel structures are recognized by the decent variety of their shapes and by their engineering expressiveness. Creation and establishment of steel structures are acknowledged through mechanical strategies.

\section{Dimensions of springs}

Table2: Selection of dimensions

\begin{tabular}{|c|c|c|c|}
\hline Sl. & Parameters & Helical springs & Wave springs \\
\hline 1. & Inner diameter $(\mathrm{mm})$ & 50 & 50 \\
\hline 2. & Outer diameter $(\mathrm{mm})$ & 57 & 60 \\
\hline 3. & Free length $(\mathrm{mm})$ & 60 & 30 \\
\hline 4. & No. of turns & 7 & 7 \\
\hline 5. & No. of Waves & 0 & 4.5 \\
\hline 6. & Wire dimension $(\mathrm{mm})$ & 3.5 & $2 \times 5$ \\
\hline
\end{tabular}

These dimensions are being taken based on coil spring used in the suspension system of Hero Honda Splendor motorcycle. The wire dimension of the wave spring is calculated based on the crosssection areas coil spring. The inner diameter is kept constant since the spring is piloted on the shaft and therefore the spring is mounted throughout the peripheral axis of the shaft. The number of turns leads to the buckling effect and increases vibrations, so as to reduce those factors wave spring is designed such a way that it consists of less number of turns as well as number of waves in which supports the upper and lower waves and thus gains more support. When the thickness of the wave spring differs, there is a chance of failure. The dimensions vary with the type of compression effect, though bike springs are meant to bear required load and to give a smooth cushion effect, whereas the spring requires a thin and more supports to bear the given load compared to the coil springs wave spring possess more supports with the no of waves and thus it attains the required results in the analysis part. Dimensions are made standard nowadays so that each material may carry up to certain level of thickness for the manufacture of springs. Depending upon those certain standard values the required design dimensions are attained.

\section{Modeling and Analysis of spring}

The design of spring is modeled in CREO parametric 4.0 by using the dimension as shown in Fig.1 (Helical spring) and fig.2 (wave spring) and analysed in ANSYS 18.0

\subsection{Equivalent Stress Analysis for Coil spring:}

For structural steel coil spring of free length is $60 \mathrm{~mm}$ and 7 turns the equivalent stress produced in coil spring is $1.1922 \mathrm{e}+006 \mathrm{Mpa}$ at $1000 \mathrm{Mpa}$ as shown in the fig. 3

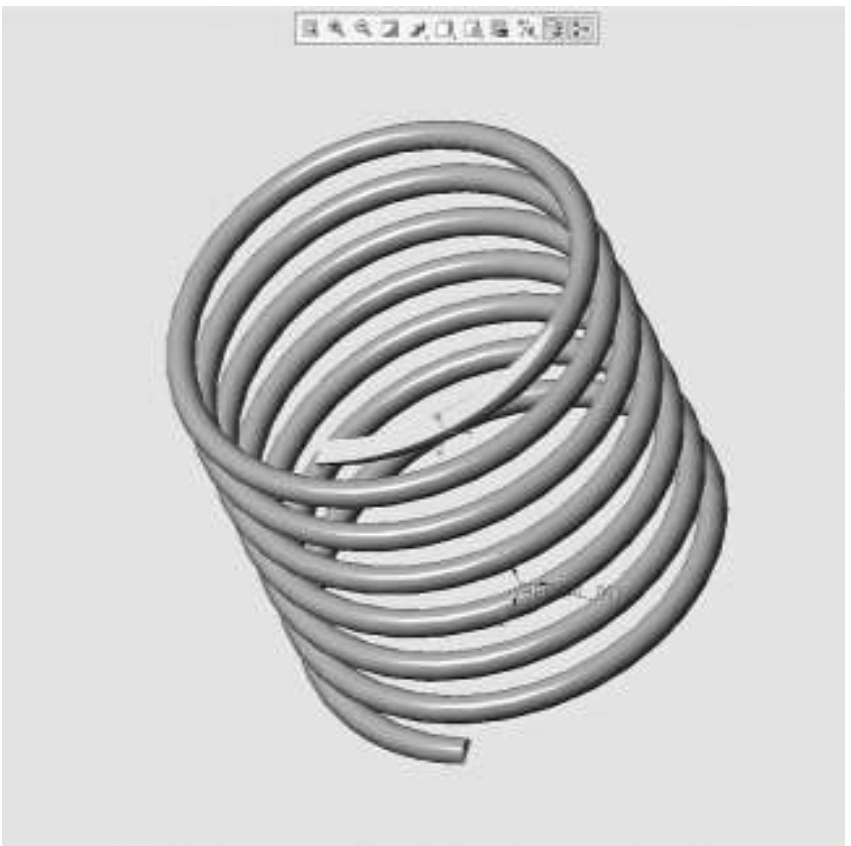

Fig.1: CADD model of helical spring in CREO

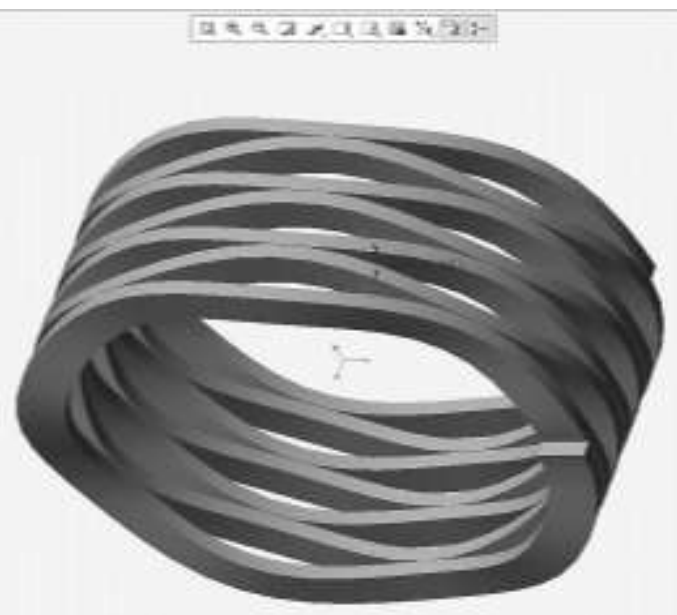

Fig.2: CADD Model of wave spring in CREO

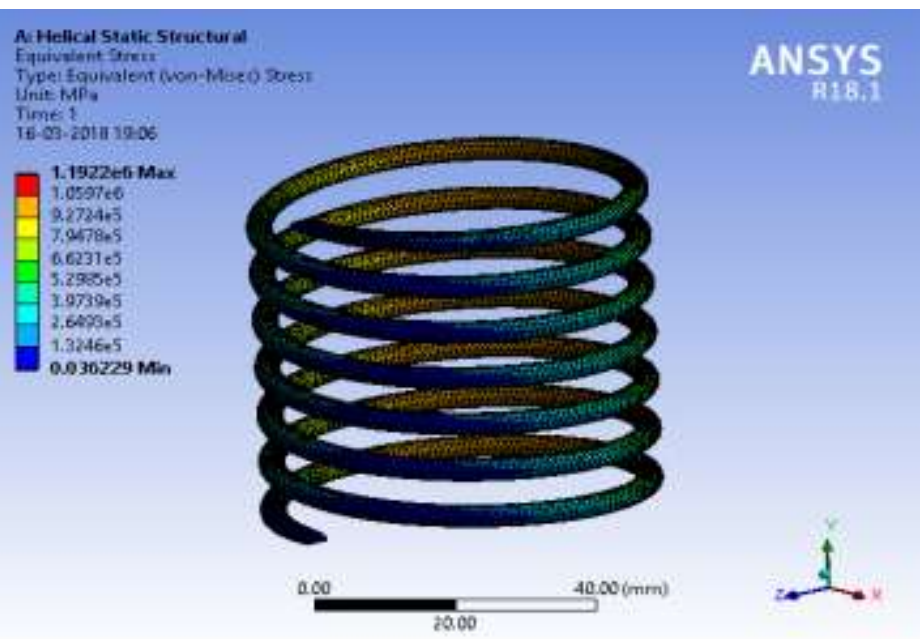

Fig.3: Equivalent Stress of Helical Spring 


\subsection{Equivalent Stress Analysis for Wave Spring:}

The structural steel of wave spring of free length is $300 \mathrm{~mm}$ and 7 turns the equivalent stress in wave spring is $3.3036 \mathrm{e}+05 \mathrm{Mpa}$ at 1000Mpa.as shown in the Fig.4

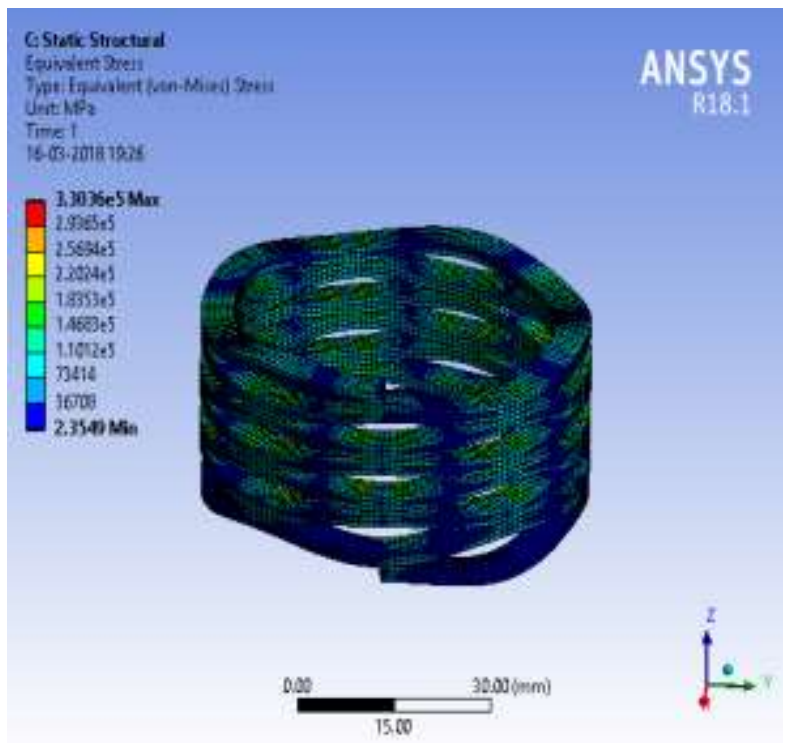

Fig.4: Equivalent stress of wave spring

\subsection{Equivalent Von-Mises Strain of Helical Spring:}

The structural steel of wave spring of free length is $300 \mathrm{~mm}$ and 7 turns the equivalent von-mises strain in wave spring is 7.3409 at a load of 1000Mpa as shown in Fig.5

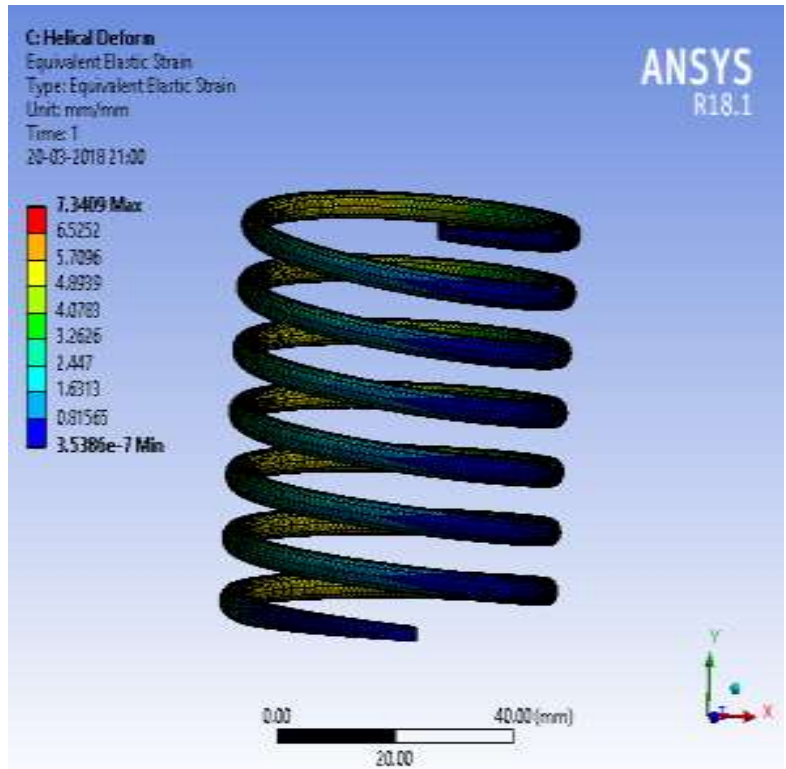

Fig.5: Equivalent (von-Mises) strain of helical spring

\subsection{Equivalent Von-Mises Strain of Wave Spring:}

The equivalent von-mises strain in wave spring is 1.6518 at a load of 1000Mpa as shown in Fig.6

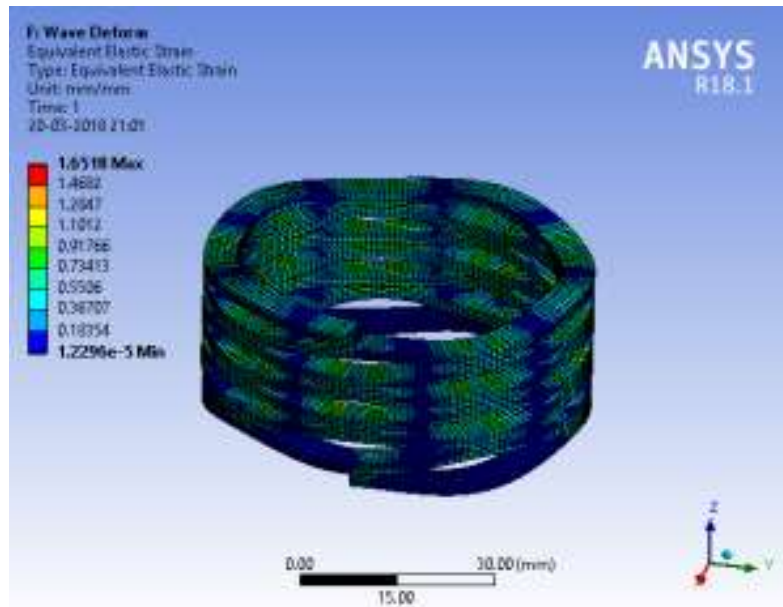

Fig.6: Equivalent (von-Mises) strain of wave spring

\section{Result and Discussion}

\section{1stress Analysis:}

The finite element analysis has been carried out for helical and wave spring by considering structural steel as material and result are compared below. The graph shows the comparison of maximum equivalent stress Vs load for coil spring and wave spring by varying loads from 100 to $1000 \mathrm{Mpa}$. As the compressive load is constantly an increase by $100 \mathrm{~N}$. As load increases, equivalent stress also increases. The equivalent stress of wave spring is less than the coil spring. The average variation of equivalent stress in wave spring is $72 \%$ less than the coil spring. As equivalent stress increases, stiffness will decrease and equivalent stress decreases, stiffness will increase. Finally, the average stress in wave springs is decreases $72 \%$ less than the helical spring and the stiffness of wave spring is higher than the helical spring.

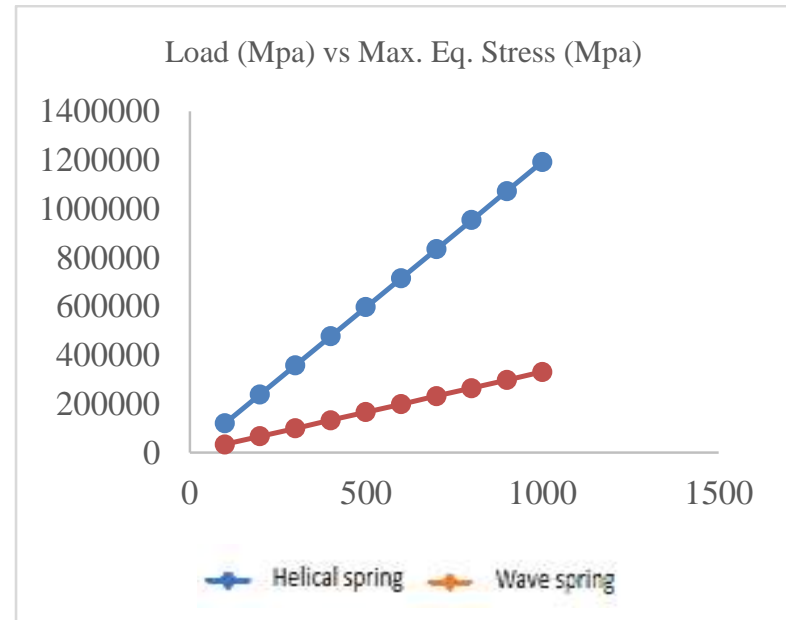

Fig.7: Comparison of load and equivalent maximum stress

\subsection{Equivalent Strain Analysis:}

The finite element analysis has been carried out for helical and wave spring by considering structural steel as material and results are compared below. 
Load (Mpa) vs Maximum Strain

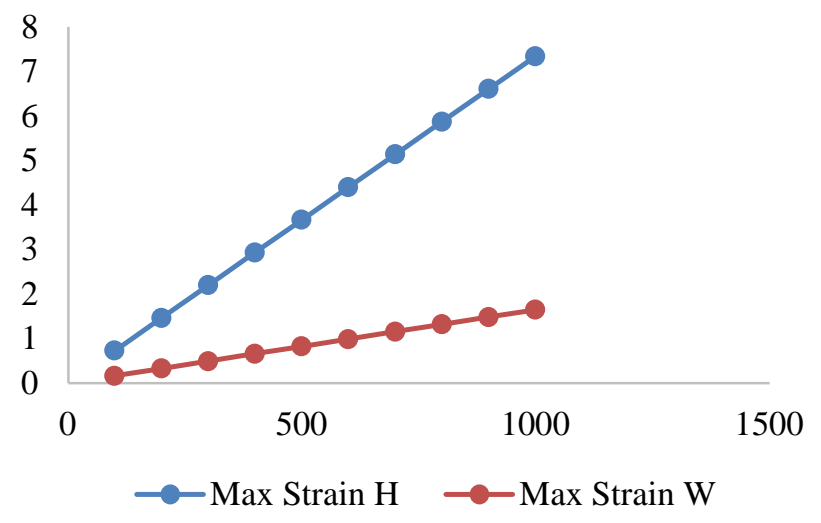

Fig.8: Comparison of load and maximum equivalent strain

The above graph shows the equivalent von-Mises strain variation of helical and wave springs. The load is constantly increased by $100 \mathrm{~N}$ from $100 \mathrm{~N}$ to $1000 \mathrm{~N}$ and then corresponding equivalent von-Mises strains are taken. The results show that helical spring has more equivalent strain when compared to that of the strain in wave spring. The equivalent von-Mises strain induced in wave spring is $77 \%$ lesser than the strain in helical spring. As the strain increases with increase in deformation, it can be inferred that wave spring has lesser deformation than helical spring.

\subsection{Modal Analysis}

Modal analysis has been done on both helical and wave spring and the deformation values are taken. From the deformation values of both the springs, it is concluded that wave spring has $4 \%$ lesser deformation than helical spring under natural conditions. Comparing the natural frequencies of both the springs, the natural frequencies of the wave spring is considerably lower compared to those values of helical springs.

Table.4: Maximum and Minimum deformation values of modal analysis of Helical Spring

\begin{tabular}{|c|cc|}
\hline Object Name & Total Deformation \\
\hline \multicolumn{2}{|c|}{ Results } \\
\hline Minimum & \multicolumn{2}{c|}{$0.52 \mathrm{~mm}$} \\
\hline Maximum & 208.52 \\
\hline \multicolumn{3}{|c|}{ Information } \\
\hline Frequency & & $26.342 \mathrm{~Hz}$ \\
\hline
\end{tabular}

Table.5: Maximum and Minimum deformation values of modal analysis of Wave Spring

\begin{tabular}{|c|c|}
\hline Type & Total Deformation \\
\hline \multicolumn{2}{|c|}{ Results } \\
\hline Minimum & $0 . \mathrm{mm}$ \\
\hline Maximum & $201.2 \mathrm{~mm}$ \\
\hline \multicolumn{2}{|c|}{ Information } \\
\hline Frequency & $22.903 \mathrm{~Hz}$ \\
\hline
\end{tabular}

\section{Conclusions}

Analysis on wave spring has been done by structural mechanics approach and results were validated and compare with the helical spring of shock absorber. The equivalent stress of wave spring is an average $72 \%$ less than the coil spring. The equivalent strain of wave spring is an average $77 \%$ less than the coil spring. So, it can be concluded deformation is less in wave spring than the coil spring. The natural frequency of wave spring is considerably lower compared to those values of helical springs.

The above result shows that the wave spring is better than the coil spring.From this project we can conclude that all type of compression coil spring can be replaced by the wave spring and it reduces the working height by $50 \%$ and reduces the material requirement and cost of the spring.

\section{Acknowledgement}

We would like to show our gratitude to all those who gave us their support.

\section{References}

[1] Prof. Dhruv Joshi, Santosh Srivastava S., Bhautik Patel R., Mehul Gohil M , "Analysis of Wave Spring and Compared with Coiled Spring for Same Parameter", IJARIIE-ISSN(O)-2395-4396, Vol-3 Issue-2, (2017).

[2] Dr P. Ravinder Reddy, V. Mukesh Reddy, "Determination of Buckling Loads of Wave Spring Using Ansys". Volume 3 Issue 8, (August. 2015),PP.48-56.

[3] Pinjarla. Poornamohan, Lakshmana Kishore. (2014) T. "Design and Analysis of a shock Absorber". International Journal of Research in Engineering and Technology, Volume: 01 Issue: 04, (Dec-2012) 2319-1163.

[4] Siddhant. R. Patil, Priyanka P. Gangurde. "Comparative Study of Wave Spring and Coil Spring Using Ansys". Journal of Computer Aided Manufacturing and Automation, Volume 2 Issue 3, (2017).

[5] P.N.L. Pavania, B.K.Prafullab, R.Polaraoc, S.Srikirand. "Modeling and Structural Analysis of wave Springs". Procedia Materials Science6, (2014), 988 - 995.

[6] Mr.Siddhant R.Patil, Prof.Poonams.Talmale, Kct's Lat G.N. Sapkal C.O.E. Nashik. "A Comparative Study of wave and Coil Spring Using Fem Approach". International Engineering Research Journal, (2016), Page No 762-767.

[7] Akshat Jain, Arun Jindal, Prateek Lakhiani, Sheelam Mishra "Mathematical Approach to Helical and Wave Spring Used in Suspension System". International Journal of Mechanical and Production Engineering, ISSN: 2320-2092, Volume- 5, Issue-6, (Jun.2017).

[8] Kalpesh Tank, Kishan Patel, Punit Sanghavi. "Material Optimization of Automotive Shock Absorbers". International Journal of Innovative Research in Science, Engineering and Technology. Vol. 5, Issue 12, December 2016.

[9] Johnson, Davis Jose, Anthony Tony. "Design and Analysis of a Shock Absorber". International Journal of Scientific \& Engineering Research, Volume 7, Issue 3, March-2016.

[10] Prince Jerome Christopher J, Pavendhan R (2016). "Design and Analysis of Two-Wheeler Shock Absorber Coil Spring", International Conference on Advances in Engineering and Management 